\title{
Analysis of Monitoring Data of Wild Animal Passages on the Highway in the Desert of Gobi, Xinjiang
}

\author{
Zhaoming Wang ${ }^{1,2 *}$ Gang Zhou $^{3}$, Shegang Shao ${ }^{1,2}$, Xiaomin $\mathrm{Wu}^{4}$, Yufeng Zhu ${ }^{5}$, Hongfeng Zhang ${ }^{4}$ \\ ${ }^{1}$ Research Institute of Highway, Ministry of Transport, Beijing, 100088, China. \\ ${ }^{2}$ Key Laboratory of Environmental Protection Technology on Road Traffic, Ministry of Transport, Beijing, 101102, Beijing. \\ ${ }^{3}$ Xinjiang Uygur Autonomous Region Traffic Construction Administration, Urumqi, Xinjiang Province, 830002, China. \\ ${ }^{4}$ Shaanxi Institute of Zoology, Xian, Shannxi Province, 710032, China. \\ ${ }^{5}$ Zhonglu Hi-tech Transportation Technology Group co. LTD, Beijing, 100088, China.
}

\begin{abstract}
This is paper is taking the design of wildlife corridor from Mingshui to Hami section of national expressway from Beijing to Urumqi as an example. From January 2015 to May 2018, the project team monitored and studied the wildlife utilization of 13 corridors along the route from Mingshui to Hami. High utilization rate was detected with 3 channels.
\end{abstract}

\section{Introduction}

Highways are an important landscape type and have brought significant economic benefits to communities. However, highway construction may adversely affect wildlife survival through habitat fragmentation, loss, and reduced connectivity. This can lead to declines in wildlife populations and to the loss of biodiversity. Wildlife corridors are thought to be and efficient way to mitigate the isolation and fragmentation of habitat caused by highway construction and can provide safety avenues for wildlife movement between habitat patches, which facilitates gene dispersal and interflow. However, there has been little research on wildlife corridor design in China, compared to the western, developed countries. Most previous studies have focused on theoretical discussions on the types, size, design principles, and procedures for corridor construction, but the location, which is the key factor affecting corridor use by wildlife, has rarely been discussed. To verify the effectiveness of the animal corridor on the Mingshui-Hami highway, we have arranged 13 animal passages on the highway and installed infrared cameras to record the data of the animals passing through.

\section{Methodology}

(1) Infrared camera monitoring

Infrared cameras are installed near the animal passages and surrounding water sources on the Mingshui-Hami highway to monitor wildlife species, activities, and interference.

There are 19 animal passages planned to be built along the Ming-Hai highway, including 6 large and medium bridges, and the rest are all small bridges. Based on the distribution of spring eyes along the line, the clear height of the bridge, the engineering characteristics and the actual situation of human interference, 8 underpass animal passages were set up. According to the plan of "adjusting the paving height + newly-built bridge", one new bridge with a clear height of $4.5 \mathrm{~m}$, two holes, and a single-hole span of $13 \mathrm{~m}$ was added at K57 + 100 and K71 +500 of the Mingha Highway to adjust the paving There are 8 points in height and 3 points remain unchanged. After the above optimization, there are 13 animal passages in the sections of K0 K105 for Equus hemionus wild donkeys. Among them, there are 3 passages with a net height of $3.5 \mathrm{~m} \sim 4 \mathrm{~m}$, and 2 passages with a net height of $4 \mathrm{~m} \sim 4.5 \mathrm{~m}$, with a net height of more than 4.5. There are $8 \mathrm{~m}$ (inclusive) channels, with an average of about $8.1 \mathrm{~km}$, and the minimum distance between two adjacent channels is $1.55 \mathrm{~km}$ and the maximum distance is $13.99 \mathrm{~km}$, which can meet the needs of Equus hemionus wild donkeys. The specific observation plan is:

All-weather video positioning observation and infrared trigger camera observation on 8 down-through animal channels.

Select the Infrared Cameras of Indus Daquan, Liujiaquan, Indus Wozi Springs near the highway along the line to observe the use of water by wild animals.

Set two control observation points on the continuous bridge-free distribution section of the starting point of the line.

Infrared cameras are set up at the lower bridges with lower clear height along the line to observe the utilization of wildlife and determine the minimum clear bridge height that can be used by wild animals.

"Corresponding author's e-mail: wangzhaoming1984@163.com. 
Table 1. Animal Corridor for Selection

\begin{tabular}{|c|c|c|c|c|}
\hline Section & No. & Mark & Spacing & Height \\
\hline \multirow{9}{*}{1} & 1 & $\mathrm{~K} 4+120$ & $2-13.0$ & 2.30 \\
\hline & 2 & $\mathrm{~K} 14+380$ & $1-8.0$ & 3.25 \\
\hline & 3 & $\mathrm{~K} 16+753$ & $2-13.0$ & 3.17 \\
\hline & 4 & $\mathrm{~K} 23+111$ & $1-8.0$ & 3.37 \\
\hline & 5 & $\mathrm{~K} 35+795$ & $1-13.0$ & 2.56 \\
\hline & 6 & $\mathrm{~K} 36+016$ & $3-13.0$ & 2.42 \\
\hline & 7 & $\mathrm{~K} 37+570$ & $1-8.0$ & 4.65 \\
\hline & 8 & $\mathrm{~K} 46+243$ & $1-8.0$ & 3.53 \\
\hline & 9 & $\mathrm{~K} 46+534$ & $2-8.0$ & 2.56 \\
\hline \multirow{8}{*}{2} & 10 & $\mathrm{~K} 57+100$ & $2-13.0$ & l \\
\hline & 11 & $\mathrm{~K} 70+000$ & 1 & \\
\hline & 12 & $\mathrm{~K} 71+500$ & $2-13.0$ & I \\
\hline & 13 & $\mathrm{~K} 73+000$ & / & \\
\hline & 14 & $\mathrm{~K} 84+420$ & $1-13.0$ & 3.02 \\
\hline & 15 & $\mathrm{~K} 85+490$ & $1-13.0$ & 3.95 \\
\hline & 16 & K91+000 & $1-13.0$ & 3.26 \\
\hline & 17 & K95+685 & $1-13.0$ & 4.94 \\
\hline \multirow{2}{*}{3} & 18 & K102+205 & $13-30$ & 6.58 \\
\hline & 19 & $\mathrm{~K} 111+100$ & 1 & \\
\hline
\end{tabular}

\section{Data analysis}

From June 2015 to July 2019, the project team deployed 21 infrared cameras near the animal passage and surrounding water sources of the Xinjiang section of the Beijing-Xinjiang Highway. The camera data was collected for half a year and the batteries were replaced. A total of 17,442 valid photos were collected during the monitoring period. There are 161 wild animal photos, 835 domestic animals, 14487 construction vehicles, and 1959 construction personnel.

\section{Results}

(1) Monitoring results during construction

During the construction of the road, only sand foxes and Equus hemionus rabbits were monitored using animal channels for migration, and domestic animals were only monitored for domestic dogs using animal channels for migration, and the frequency of monitoring was very low, including four monitoring's of sand foxes and six of Equus hemionus rabbits. 3 domestic dogs. During the highway construction period, construction vehicles and construction personnel frequently interfered with the wildlife utilization channel through the animal channel.

Table.2 Statistical table of wildlife passages during the construction period of Mingha Highway

\begin{tabular}{c|r|r|r|l|c}
\hline Site & \multicolumn{1}{|c|}{ Date } & \multicolumn{1}{c|}{ Time } & \multicolumn{1}{|c|}{ Working Day } & Wildlife's Name & Photos \\
\hline K71+500 & $2016 / 7 / 15$ & $3: 22$ & 1 & Corsac & 1 \\
\hline K102+205 & $2016 / 9 / 26$ & $19: 48$ & 31 & Corsac & 1 \\
\hline K71+500 & $2016 / 10 / 19$ & $5: 54$ & 97 & Corsac & 1 \\
\hline K71+500 & $2017 / 2 / 7$ & $1: 59$ & 207 & Corsac & 1 \\
\hline
\end{tabular}




\begin{tabular}{l|r|r|r|l|l}
\hline $\mathrm{K} 102+205$ & $2017 / 4 / 20$ & $1: 51$ & 236 & $\begin{array}{l}\text { Equus hemionus } \\
\text { rabbit }\end{array}$ & 1 \\
\hline $\mathrm{K} 102+205$ & $2017 / 4 / 20$ & $4: 51$ & 236 & $\begin{array}{l}\text { Equus hemionus } \\
\text { rabbit }\end{array}$ & 1 \\
\hline $\mathrm{K} 102+205$ & $2017 / 4 / 28$ & $1: 34$ & 244 & $\begin{array}{l}\text { Equus hemionus } \\
\text { rabbit }\end{array}$ & 1 \\
\hline $\mathrm{K} 102+205$ & $2017 / 5 / 12$ & $5: 17$ & 258 & $\begin{array}{l}\text { Equus hemionus } \\
\text { rabbit }\end{array}$ & 1 \\
\hline $\mathrm{K} 102+205$ & $2017 / 5 / 17$ & $5: 10$ & 263 & $\begin{array}{l}\text { Equus hemionus } \\
\text { rabbit }\end{array}$ & 1 \\
\hline $\mathrm{K} 102+205$ & $2017 / 5 / 21$ & $4: 06$ & 267 & $\begin{array}{l}\text { Equus hemionus } \\
\text { rabbit }\end{array}$ & 1 \\
\hline
\end{tabular}

(2) Monitoring results during operation period

After the operation of the highway, 7 wild animals including Equus hemionus wild donkeys, Gazella subgutturosa, wolves, jackals, sand foxes, Equus hemionus rabbits, and weasels were monitored using animal channels for migration. Among them, Gazella subgutturosa used channels up to 54 times, and Equus hemionus wild asses and weasels used animals the channel frequency is at least once, and the frequency of other wild animals using animal channels is between the two. In terms of domestic animals, 5 domestic animals, including domestic sheep, domestic camels, domestic donkeys, domestic horses, and domestic dogs, were monitored using animal channels for migration. The domestic camels used animal channels up to 299 times and domestic horses used animal channels at least 4 Second, other livestock utilization channels are somewhere in between.

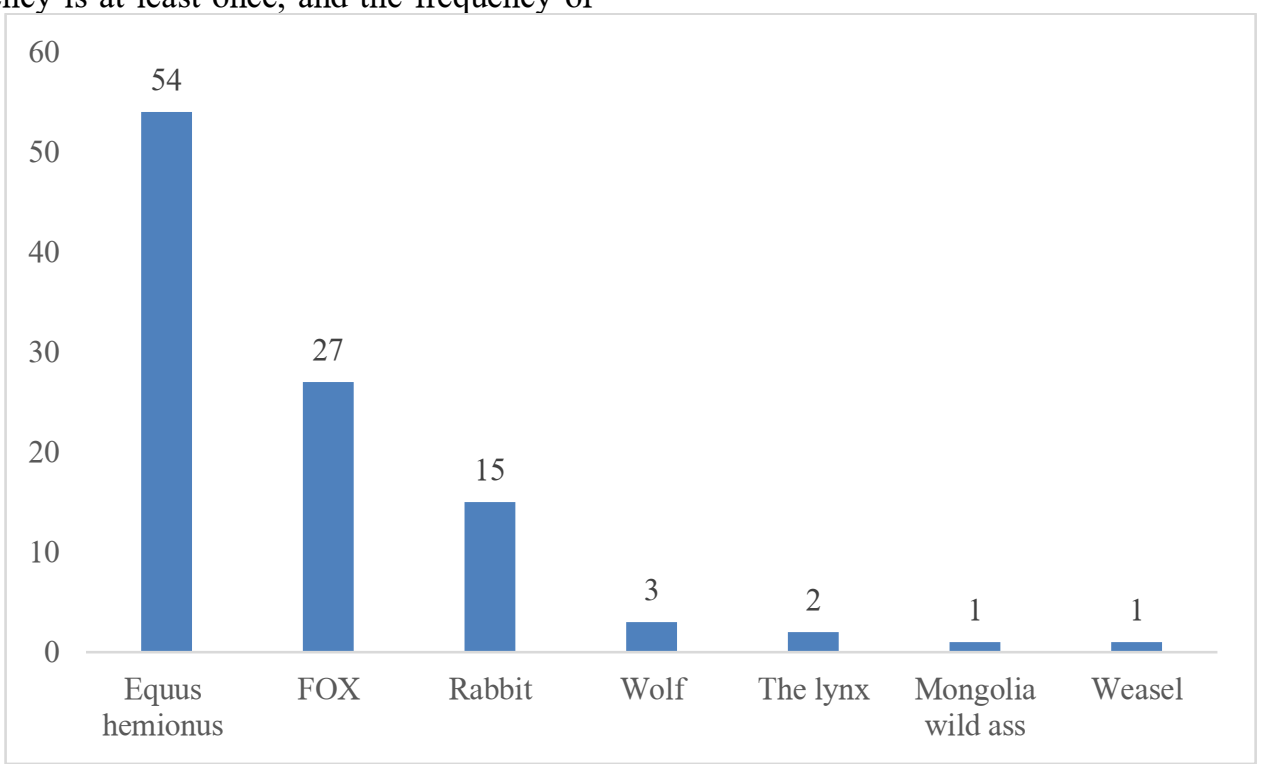

Fig.1 Statistics of Wild Animal Utilization in Mingha Highway

\section{Controlling air pollution}

(1) Prefabricated yards, mixing stations, stockyards and other places that generate a lot of atmospheric dust shall be set in open areas in the downwind direction of sensitive areas of wildlife, with a distance of at least $300 \mathrm{~m}$.

(2) It is strictly forbidden to occupy wetland and keep it away from wild animal habitats as much as possible; dustproof measures such as sealing or shielding and moisturizing shall be adopted in the stockyard.

(3) Sprinkling water and dust-reducing measures shall be taken on working surfaces and construction processes prone to wind and dust.

(4) For some highly polluting wastes, such as toxic liquid, phosphorous slag, slag, fly ash, etc., closed transportation should be adopted, and the site should be cleaned as soon as possible.
(5) Take hardening, water spraying and dust reduction measures at the construction site to avoid dustprone construction operations in windy weather.

\section{Controlling sewage}

(1) Construction wastewater such as prefabrication yards and mixing stations should be reused after precipitation or sprinkled to reduce dust, and not directly discharged.

(2) The domestic sewage in the construction camp shall be treated with dry toilets or septic tanks, and shall be cleaned and transported regularly.

\section{Solid waste control}

(1) Domestic garbage should be collected by classification and concentrated, and cleaned up, cleared or disposed on-site in time. 
(2) The construction waste is collected and recycled after centralized collection, and cannot be used for disposal at the designated spoil ground.

(3) During the construction of the project, no littering and harmful substances shall be allowed to harm wild animals.

(6) Use transportation vehicles and non-road mobile machinery that meet pollutant discharge standards to standardize the construction material transportation routes, and cover measures for material transportation.

(7) Asphalt concrete mixing equipment with good sealing performance, high dust removal efficiency and low pollution discharge is used for material mixing.

(8) When the excavated bare site is not under construction, it should be covered with dust screens and sprinkled regularly to reduce dust pollution.

\section{Acknowledgments}

NSFC (Natural Science Foundation of China, 4161183, "Study on the impact of road network on habitat safety of large wildlife in xinjiang's typical desert and gobi region". Xinjiang construction and communications bureau science and technology project "Research and demonstration of key technologies for wildlife passage construction in desert and gobi region".

\section{References}

1. Van der Geer, J., Hanraads, J.A.J., Lupton, R.A. (2010) The art of writing a scientific article. J. Sci. Commun., 163: 51-59.
2. Brodie, J.F., Paxton, M., Nagulendran, K., Balamurugan, G., Clements, G.R., Reynolds, G., Jain, A., Hon, J., 2016. Connecting science, policy, and implementation for landscape-scale habitat connectivity. Conserv. Biol. 30, 950-961.

3. Elliot, N.B., Cushman, S.A., Macdonald, D.W., Loveridge, A.J., 2014. The devil is in the dispersers: predictions of landscape connectivity change with demography. J. Appl. Ecol. 51, 1169-1178.

4. Forman, R.T.T., Alexander, L.E., 1998. Roads and their major ecological effects. Annu. Rev. Ecol. Syst. 29, 207-231.

5. KAZA TFCA Secretariat, 2014. Kavango-Zambezi Transfrontier Conservation Area: Master Integrated Development Plan, 2014-2019. KAZA TFCA Secretariat, Kasane, Botswana.

6. Kiffner, C., Albertini, M., Ede, A., Donnellan, B., Hahn, N., McGinnis, M.A., Nietlisbach, N.A., Tate, J., Kioko, J., 2015. Performance of individual species as indicators for large mammal species richness in Northern Tanzania. Ecol. Indic. 53, 7077.

7. Naidoo, R., Du Preez, P., Stuart-Hill, G., Beytell, P., Taylor, R., 2014. Long-range migrations and dispersals of African buffalo (Syncerus caffer) in the Kavango-Zambezi Transfrontier Conservation area. Afr. J. Ecol. 52, 581-584.

8. Naidoo, R., Chase, M.J., Beytell, P., Du Preez, P., Landen, K., Stuart-Hill, G., Taylor, R., 2016. A newly discovered wildlife migration in Namibia and Botswana is the longest in Africa. Oryx 50, 138-146. 